Варлен М. В., Зенин С. С.

К ВОПРОСУ О ГОТОВНОСТИ ЮРИДИЧЕСКИХ
ЛИЦ, ОСУЩЕСТЛЯЮЩИХ ГЕНЕТИЧЕСКОЕ
ТЕСТИРОВАНИЕ, СТАТЬ САМОРЕГУЛИУЕМЫМИ
ОРГАНИЗАИЯМИ В ЮРИСДИКЦИИ
РОССИЙСКОЙ ФЕДЕРАЦИИ

Varlen M. V., Zenin S. S.

\title{
ON THE WILLINGNESS OF LEGAL ENTITIES CONDUCTING GENETIC TESTING TO BECOME SELF-REGULATORY ORGANIZATIONS IN THE JURISDICTION OF THE RUSSIAN FEDERATION2
}

\begin{abstract}
Рассмотрены вопросы формирования саморегулируемых организаций в оказании медицинских услуг населению. Среди саморегулируемых организаций практически нет организаций в области геномного консультирования. Обсуждается вопрос о перспективах появления в Российской Федерации организаций, оказывающих услуги по расшифровке генома (экзома) на основе принципов саморегулирования и в соответствии с Российским законодательством. Высказана необходимость формирования ассоциации специалистов в области геномных исследований.

Ключевые слова: правовое регулирование, саморегулирование, саморегулируемые организации (СРО), генетическое тестирование, защита прав потребителя.
\end{abstract}

The issues of the formation of self-regulatory organizations in the provision of medical services to the population are considered. Among the self-regulatory organizations, there are practically no organizations in the field of genomic counseling. The issue of prospects for the emergence in the Russian Federation of organizations providing services for decoding the genome (exome) based on the principles of self-regulation and in accordance with Russian legislation is discussed. The necessity of forming an association of specialists in the field of genomic research is expressed.

Keywords: legal regulation, self-regulation, self-regulatory organizations (SROs), genetic testing, consumer protection.

Развитие использования результатов расшифровки генома человека и начало широкого внедрения генетического типирования, внедрение технологии генетического тестирования ставит большой круг юридических вопросов, урегулирование которых необходимо для развития этой сферы деятельности. Одним из актуальных вопросов является развитие практики саморегулирования. Прежде всего рассма-

1 Исследование выполнено при финансовой поддержке Российского фонда фундаментальных исследований (РФФИ) в рамках научного проекта № 18-29-14058.

2 The reported study was funded by RFBR according to the research project № 18-29-14058. 
тривается вопрос существования саморегулируемых организаций в сфере практики геномных исследований и оказания геномных услуг. Сложность заключается в том, что необходимость решения юридических вопросов ощущается раньше, чем в России сформировалась практика саморегулируемых организаций в области геномных исследований. Такой подход оправдан, т. к. в условиях бурного развития биотехнологии встают вопросы этического и правого характера, касающиеся личности, субъектов коммерческой и некоммерческой деятельности и регулирующей роли государства. Этические вопросы геномных исследований давно стали предметом рассмотрения международного права.

Если говорить о Российской Федерации, можно говорить о существующей системе противоречий в этой области. С одной стороны, у нас существует закон о саморегулируемых организациях[1], охватывающий как коммерческую, так и некоммерческую сферу, с другой стороны российская практика некоммерческих медицинских организаций относительно бедна.

За последние годы наблюдается рост саморегулируемых организаций медицинской направленности [2]. Большую часть из них объединяет СРО «Национальная Ассоциация медицинских организаций». Если в 2015 году было зарегистрировано 15 саморегулируемых организаций - 14 по предпринимательскому типу и одна - по профессиональному (сама СРО «Национальная Ассоциация медицинских организаций») [3] то в 2017 году общее число членов СРО достигло 196 из 49 субъектов Российской Федерации. Более 20 юридических лиц, входящих в СРО, имеют обособленные подразделения. Общее число адресов, где осуществляется медицинская деятельность членов СРО, составляет 231. Общий доход членов СРО в 2017 году составил более 13 млрд рублей[4]. В 2018 году общий доход медицинских организаций, входящих в СРО «Национальная Ассоциация медицинских организаций», составил более 20 млрд. рублей [5].

Вместе с тем среди указанных медицинских СРО (во всяком случае в ТОП 50) отсутствуют организации, занимающиеся исследованием индивидуального генома (экзома), есть только несколько организаций, занимающихся вспомогательными репродуктивными технологиями.

Рынок геномных исследований в России пребывает «в полутени». В этом отношении представляет интерес выступление главного редактора Журнала «Гены и клетки» ${ }^{1}$ Артура Исаева 28 февраля 2020 г.

1 http://genescells.ru/o-zhurnale/
На площадке интернет версии журнала он опубликовал материал «О дискриминации российского бизнеса генетических исследований» [6], в котором сообщается, что депутат Госдумы Евгений Фёдоров направил запрос в Генпрокуратуру с просьбой проверить законность сбора ДНК-данных граждан России международной социальной сетью MyHeritage.

Далее приводим текст, который следует понимать как авторское мнение А. Исаева:

«Исходя из интересов развития отрасли, не должно быть дискриминационных условий у российских лабораторий, которые производят исследования генома, генетические исследования и сиквенс в России. Такие лаборатории, которые работают в интересах клиник и пациентов, получают медицинские лицензии и отвечают по закону РФ о защите потребителей. А зарубежные лаборатории, которые по факту не проходят никакого лицензирования у российского регулятора и не находятся под действием российского закона, но при этом фактически свободно продают свои услуги россиянам через посредников, которые прячутся под маской "лабораторий" или "медицинских центров" - а по факту и смыслу бизнеса просто дистрибьютеры зарубежных лабораторий. Никаких инвестиций в РФ, никакого медицинского персонала и рабочих мест здесь не имеют и им нет необходимости получать лицензии и разрешения у регулятора в России, они не несут никакой ответственности по российским законам. И при этом свободно продают услуги неграмотным пациентам, вывозя их образцы.

Чтобы было понятно - ни одна российская лаборатория не сможет сотрудничать с американской медицинской клиникой и не имеет права оказывать медицинские услуги американцам без разрешения американского регулятора. Да такого и не произойдёт, так как клиники не рискнут пойти на это, ведь цена иска от пациентов, как правило, очень высока. В России такие же законы по смыслу и сути, но регуляторы в РФ и потребители законами в России пользуются в редких случаях. И в России спокойно оказывают услуги зарубежные лаборатории без выполнения российских законов.» ${ }^{2}$ [6]

Следует отметить, что среди топовых центров по коммерческому секвенированию [7], постулирующих свою российскую принадлежность, фигурируют организации, сотрудники которых представляют себя как научные работники зару-

2 http://genescells.ru/news/o-diskriminatsii- 
бежных научных центров с собственными интересами, среди них почти нет лиц с биологическим и тем более медицинским образованием, не все центры имеют медицинскую лицензию, иногда она оформлена на юридическое лицо, не соответствующее названию фирмы.

Исходя из выше изложенного, следует сказать, что наличия закона о саморегулировании недостаточно для нормализации положения в области развития прикладных геномных исследований. В зарубежных странах, особенно странах с прецедентным правом, деятельность в области прикладных геномных исследований нашла свою юридическую нишу, вместе с тем подвергаясь корректирующему воздействию национальных регуляторов [8].

Открытым остается вопрос, кто выступит в нашей стране инициатором создания единой саморегулируемой организации в области геномных исследований на некоммерческой основе или организации наподобие СРО «Национальная Ассоциация медицинских организаций»

Если медицинское сообщество ощущает необходимость формирования некоммерческих медицинских ассоциаций, то специалисты, занимающиеся расшифровкой генома, такой потребности не ощущают, так как вследствие своих профессиональных особенностей (специалисты в области биоинформатики, физики, химии) не связаны этическими корпоративными обязательствами.

Мало того, если мы говорим о саморегулируемых организациях, они должны отвечать определенным требованиям [9]. Необходимо провести большую работу по:

1) выработке стандартов профессиональной деятельности и правил коммерческой деятельности;

2) выработке санкций за нарушение стандартов и правил;

3) разработке действенной системы мониторинга профессиональной деятельности;

4) разработке механизма осуществления контрольных функций вплоть до применения санкций в случае обнаружения нарушения установленных стандартов и правил;

5) разработке и реализации процедуры внесудебного разрешения спорных вопросов (как между членами организации, так и организацией и ее членами);

6) разработке протоколов рассмотрения жалоб на деятельность членов организации (на нарушение ими правил организации);

Кроме того, желательно предусмотреть внесудебное разрешение споров (прежде всего потребителей) с членами организации и компенсацию вреда, причиненного вследствие неправомерной деятельности члена СРО по отношению к третьим лицам.

Следует задать вопрос, а можем ли мы обеспечить достаточность представительства субъектов предпринимательской и профессиональной деятельности ввиду относительно низкой на сегодняшний день потребности в индивидуальной расшифровке генома.

Отдельным пунктом повестки дня в области геномных исследований стоит вопрос о защите генетической информации граждан Российской Федерации, что нашло свое отражение в государственных решениях по вопросам обеспечения химической и биологической безопасности в рамках осуществления мониторинга химических и биологических рисков - вопрос о генетической паспортизации населения с учетом правовых основ защиты данных о персональном геноме человека и формирование генетического профиля населения [10].

Таким образом, перед научным медицинским сообществом стоит задача решить проблемы, связанные с выработкой критериев осуществления деятельности в области геномного тестирования, хранения этой информации и интерпретации результатов тестирования. Очевидно, такого рода площадкой могла бы стать Российская академия наук, объединяющая наиболее компетентных специалистов в области генетики и медицины.

\section{Литература}

1. Федеральный закон "О саморегулируемых организациях" от 01.12.2007 № 315-Ф3.

2. Борисов Д.А., Лазарев С.В., Мисюлин С.С. Саморегулируемые организации в здравоохранении 09.06.2010 11:05:40 https://www.remedium.ru/health/detail. php?ID=36183

3. Мисюлин С.С. Саморегулируемые организации в медицине. Кто есть кто. Информационный ресурс для руководителей частных медицинских организаций. 27.11.2015. http://www. privatmed.ru/article/36/1247/2041/.

4. Мисюлин С.С. Новости уходящего года от Национальной ассоциации медицинских организаций. Информационный ресурс для руководителей частных медицинских организаций 20.12.2018 http://www.privatmed.ru/ article/36/1124/2385/. 
5. Мисюлин С.С. Итоги 2019 года. ТОП-50 членов нвциональной ассоциации медицинских организаций. 30.12.2019. http://www.privatmed.ru/ article/36/1124/2502/.

6. Исаев А.А. О дискриминации российского бизнеса генетических исследований. 28.02.2020 http://genescells.ru/news/o-diskriminatsii-rossiyskogo-biznesageneticheskih-issledovaniy/.

7. Гид по генетическим тестам в России: какой выбрать и где заказать. 20.02.2018. https://vc.ru/life/32760-gid-po-geneticheskim-testam-v-rossii-kakoyvybrat-i-gde-zakazat.

8. Сахипгареева А.Р. Государственный контроль интерпретации геномных исследований и медицинских приложений в Соединенных Штатах Америки Вестник РУДН. Серия: Юридические науки 2018 Т. 22. № 3. 329-345.

9. Ряховская А.Н., Федотова М.А., Ветрова И.Ф. Проблемы саморегулирования в России. Эффективноеантикризисноеуправление. 2010. № 4 (63). С. 38-46.

10. Указ Президента РФ от 11 марта 2019 г. № 97 "Об Основах государственной политики Российской Федерации в области обеспечения химической и биологической безопасности на период до 2025 года и дальнейшую перспективу".

\section{References}

1. Federal'nyyzakon "O samoreguliruyemykh organizatsiyakh" ot 01.12.2007 № 315-FZ

2. Borisov D.A., Lazarev S.V., Misyulin S.S. Samoreguliruyemyye organizatsii v zdravookhranenii 09.06.2010 11:05:40 https://www.remedium.ru/health/detail. php?ID=36183.

3. Misyulin S.S. Samoreguliruyemyye organizatsii v meditsine. Kto yest' kto. Informatsionnyy resurs dlya rukovoditeley chastnykh meditsinskikh organizatsiy.27.11.2015.http://www. privatmed.ru/article/36/1247/2041/.

4. Misyulin S.S. NovostiukhodyashchegogodaotNatsional'noyassotsiatsiimeditsins kikhorganizatsiy. Informatsionnyyresursdlyarukovoditeleychastnykhmeditsinskikhor ganizatsiy 20.12.2018 http://www. privatmed.ru/article/36/1124/2385/.

5. Misyulin S.S. Itogi 2019 goda. TOP-50 chlenov nvtsional'noy assotsiatsii meditsinskikh organizatsiy. 30.12.2019. http://www. privatmed.ru/ article/36/1124/2502/.

6.Isayev A.A. O diskriminatsii rossiyskogo biznesa geneticheskikh issledovaniy. 28.02.2020 http://genescells.ru/news/o-diskriminatsii-rossiyskogo-biznesageneticheskih-issledovaniy/.

7. Gidpo geneticheskim testam v Rossii: kakoyvybrat' i gde zakazat'. 20.02.2018. https://vc.ru/life/32760-gid-po-geneticheskim-testam-v-rossii-kakoy-vybrat-i-gdezakazat.

8. Sakhipgareyeva A.R. Gosudarstvennyy kontrol' interpretatsii genomnykh issledovaniy i meditsinskikh prilozheniy v Soyedinennykh Shtatakh Ameriki Vestnik RUDN. Seriya: Yuridicheskiye nauki 2018 T. 22. № 3. 329-345.

9. Ryakhovskaya A.N., Fedotova M.A., Vetrova I.F. Problemy samoregulirovaniya v Rossii. Effektivnoyeantikrizisnoyeupravleniye. 2010. № 4 (63). S. 38-46.

10. UkazPrezidenta RF ot 11 marta 2019 g. № 97 "Ob Osnovakhgosudarstvennoy politiki Rossiyskoy Federatsii v oblasti obespecheniya khimicheskoy i biologicheskoy bezopasnosti na period do 2025 goda i dal'neyshuyu perspektivu".

ВАРЛЕН Мария Викторовна, доктор юридических наук, доцент, директор Института аспирантуры и докторантуры ФГБОУ ВО «Московский государственный юридический университет имени О.Е. Кутафина (МГЮА)». 125993, г. Москва, ул. Садовая-Кудринская, дом 9. E-mail: mvvarlen@msal.ru

ЗЕНИН Сергей Сергеевич, кандидат юридических наук, доцент, директор Научно-исследовательского института ФГБОУ ВО «Московский государственный юридический университет имени О.Е. Кутафина (МГЮА)». 125993, г. Москва, ул. Садовая-Кудринская, дом 9. E-mail: zeninsergei@mail.ru

VARLEN Maria, doctor of law, associate professor, director of the Institute of postgraduate and doctoral studiesof FSBOU VO "Moscow State Law University named after O.E. Kutafin (Moscow State University)." 125993, Moscow, Sadovaya-Kudrinskayastreet, house 9. E-mail: mvvarlen@msal.ru

ZENIN Sergey, Candidate of Legal Sciences, Associate Professor, Director of the Research Institute of the Federal State Budgetary Educational Institution of Higher Education "Moscow State Law University named after O.E. Kutafina (Moscow State Law Academy) ". 125993, Moscow, st. Sadovaya-Kudrinskaya, house 9. E-mail: zeninsergei@mail.ru 